\title{
Medication non-adherence: an overlooked target for quality improvement interventions
}

\author{
Bryony Dean Franklin (D) , ${ }^{1,2}$ Gary Abel (D) , ${ }^{3}$ Kaveh G Shojania ${ }^{4}$
}

${ }^{1}$ Centre for Medication Safety and Service Quality, Imperial College Healthcare NHS Trust I UCL School of Pharmacy, London, UK

${ }^{2}$ Department of Practice and Policy, UCL School of Pharmacy, London, UK

${ }^{3}$ Medical School (Primary Care), University of Exeter, Exeter, UK ${ }^{4}$ Department of Medicine, University of Toronto Faculty of Medicine, Toronto, Ontario, Canada

\section{Correspondence to}

Professor Bryony Dean Franklin, Director, Centre for Medication Safety and Service Quality, Imperial College Healthcare NHS Trust / UCL School of Pharmacy, London, W6 8RF, UK ; bryony.franklin@nhs.net

Accepted 6 December 2019 Published Online First 20 December 2019

\section{Sinked}

- http://dx.doi.org/10.1136/ bmjqs-2018-009177

\section{Check for updates}

(C) Author(s) (or their employer(s)) 2020. No commercial re-use. See rights and permissions. Published by BMJ.

To cite: Franklin BD, Abel G, Shojania KG. BMJ Qual Saf 2020;29:271-273.
Quality improvement initiatives often focus on closing the gap between routine practice and the care recommended in guidelines-ensuring, for instance, that patients with chronic conditions receive prescriptions for medications demonstrated to improve health outcomes. However, this focus often ignores the even more basic problem: that many patients prescribed medicines for chronic conditions take them inconsistently or not at all. In one US study, ${ }^{1}$ patients who had recently experienced a myocardial infarction took key medicines intended to prevent further cardiac events only $35 \%-50 \%$ of the time, depending on the class of medication. Perhaps surprisingly, providing the medicines for free improved adherence by only a few percentage points. Other studies also report adherence rates of around $50 \%$ or less. ${ }^{2-5}$

Medication adherence thus constitutes one of the 'big hairy problems' or 'big hairy audacious goals" ${ }^{3}$ of healthcare. As well as affecting patients' long-term outcomes, non-adherence can increase healthcare costs through consumption of medicines below the threshold of adherence required for clinical benefit, as well as contributing to healthcare resource use such as hospital admissions. ${ }^{7}$ Disposal of what can amount to significant quantities of unused medication also presents an under-recognised problem.

Evidence for how best to address nonadherence remains unclear, with relatively few well-designed studies. ${ }^{2}$ We therefore welcomed the opportunity to publish an initial, positive report of an intervention to improve adherence in patients prescribed a new medicine for asthma or chronic obstructive pulmonary disease, hypertension, type 2 diabetes or an anticoagulant/antiplatelet agent. ${ }^{8}$ The intervention comprised an initial interview with a pharmacist (in person or by telephone) within 7-14 days of prescription, and then a follow-up interview (by telephone) 14-21 days later. The interviews identified problems related to adherence but also any areas for which patients felt they needed further information or support. This initial study, published in 2016, presented the findings at 10-week follow-up. This revealed an absolute increase of $10 \%$ in the proportion of patients adhering to their new medicine, from $61 \%$ in the control arm to $71 \%$ in the intervention arm $(\mathrm{p}=0.04$ for unadjusted analysis) with only 37 (15\%) of patients having dropped out in the control arm and $16(6 \%)$ in the intervention arm. In an adjusted analysis taking into account clustering and potential confounders, the odds ratio was 1.67 (95\% CI 1.06 to $2.62 ; p=0.027$ ) in favour of the intervention. These results therefore suggested the intervention to have a relatively small but statistically significant benefit, with a general trend towards reduced costs for the health system ${ }^{8}$ and $97 \%$ probability of cost-effectiveness based on more detailed economic modelling. ${ }^{9}$ As a result, the English National Health Service commissioned this New Medicines Service for routine use. ${ }^{10}$

Results of a longer term follow-up of the same patients at 26 weeks are now reported by Elliott and colleagues in this issue of BMJ Quality \& Safety. Unfortunately, by 26 weeks, the proportion of adherent patients had dropped in both the control and intervention arms (to $57 \%$ and $66 \%$, respectively), with loss of statistical significance for this difference $(p=0.113) .{ }^{11}$ So what do these findings tell us about the effectiveness of the intervention, how adherence may change over time and the implications for practice, policy and research? 
First, in terms of the effectiveness of the intervention, the follow-up data leave us in a difficult position. By 26 weeks, 41 patients (16\%) had dropped out in the control arm and $25(10 \%)$ in the intervention arm, ${ }^{11}$ leaving a study that was powered based on 10 -week follow-up with less power to detect a difference by 26 weeks. It is therefore not possible to know whether the lack of statistical significance by 26 weeks is simply due to the smaller sample size and thus lower power due to further study drop-outs, the effect of the intervention itself being attenuated or a combination of the two.

Second, while the follow-up study shows that adherence generally reduces over time, as might be expected, it also suggests that it is dynamic. Between 10 and 26 weeks, some adherent patients became nonadherent $(15 \%$ of all those who were adherent at ten weeks) and non-adherent patients became adherent ( $25 \%$ of those who were non-adherent at 10 weeks). These changes occurred in similar proportions in the control and intervention arms. While a reduction in adherence to long-term medication over time is well documented, this more dynamic nature of adherence behaviour highlighted by Elliott and colleagues ${ }^{11}$ suggests a far more complex picture, together with questions about what causes a non-adherent patient to become adherent as well as vice versa. The implications of this dynamic nature of adherence for research in this area are also unclear but are likely to affect the choice of adherence measure. For example, some studies, including this work by Elliott and colleagues, consider a single time point such as adherence over the last 7 days, whereas others ask whether patients 'ever' forgot doses of their medicines. ${ }^{12}$

Third, we clearly need longer term studies to evaluate the impact of interventions aimed at improving medication adherence. Even a 26-week follow-up, as in the present paper, ${ }^{11}$ seems on the short side when assessing adherence to medications that patients will take for many years. A Cochrane review suggests 26 weeks as the minimum follow-up for studies of adherence to medications used for long-term conditions such as asthma, chronic obstructive pulmonary disease, hypertension and type 2 diabetes, for which patients are likely to need to take medications for many years and not just 6 months. ${ }^{2}$ Longer studies are therefore needed, which will also require considerable effort to minimise participant attrition over these greater time frames.

While studies lasting several years present practical challenges, perhaps the bigger challenge lies with developing effective interventions. Many commonly used solutions, from multicompartment compliance aids with sections for each day's medications to more sophisticated electronic containers and smartphone reminder apps, assume that that non-adherence simply reflects forgetfulness. For some patients, forgetting may indeed be a problem. However, for others, non-adherence is instead associated with beliefs about their need for medication, such as patients who believe that they only need to take medication for high blood pressure on days when they feel anxious or unwell.

Non-adherence can also be associated with ambivalence about the importance or desirability of taking long-term medicines, concerns over side effects ${ }^{13}$ or arise due to medication-related harm, all of which require exploration and shared decision making. Motivational interviewing, health coaching and other counselling techniques, often delivered by pharmacists, can help to address some of these more complex and often legitimate reasons patients choose not to take their medicines. ${ }^{14}$ For instance, a recent trial ${ }^{15}$ evaluated medication management tools delivered through a commercial electronic health record (EHR) with and without an accompanying nurse-led intervention educating patients about their medications aiming to support improved adherence. The intervention arm of the study involving EHR tools improved medication reconciliation but led to worse blood pressure control compared with the control group, whereas the combination of EHR tools and nurse-led education improved control. In discussing this unexpected result, the authors speculated that patients in the group receiving EHR tools only might have seen the adverse drug effects outlined on medication information sheets and stopped or reduced the medications involved. Patients in the group receiving education and counselling from nurses would have had the opportunity to ask about the seriousness or likelihood of these adverse effects and presumably felt more comfortable adhering to the prescribed antihypertensives.

The original study ${ }^{8}$ of the New Medicines Service was funded only for a 10 -week follow-up. ${ }^{11}$ It is thus commendable that the authors decided to also collect data at the 26-week point. While the intervention's benefits may not have persisted over this longer follow-up period, the results highlight the importance of further attention to this problem. So much effort by those engaged in quality improvement research and practice has focused on addressing shortfalls in the provision of evidence-based care, such as prescribing proven medicines for long-term conditions. These efforts will achieve limited impact if we continue to ignore the degree to which patients take these medications as intended and if we fail to address the often legitimate reasons for their not doing so. Moreover, just as called for in other areas of quality improvement, efforts to increase adherence will likely benefit from greater involvement by patients in developing the interventions-coproducing them with the patient groups intended to benefit. ${ }^{16-18}$

Contributors Not applicable.

Funding BDF is supported by the National Institute for Health Research (NIHR) Imperial Patient Safety Translational Research Centre. 
Disclaimer The views expressed are those of the author(s) and not necessarily those of the NHS, the NIHR, or the Department of Health and Social Care.

Competing interests None declared.

Patient consent for publication Not required.

Provenance and peer review Commissioned; internally peer reviewed.

\section{ORCID iDs}

Bryony Dean Franklin http://orcid.org/0000-0002-2892-1245

Gary Abel http://orcid.org/0000-0003-2231-5161

\section{REFERENCES}

1 Choudhry NK, Avorn J, Glynn RJ, et al. Full coverage for preventive medications after myocardial infarction. $\mathrm{N}$ Engl J Med 2011;365:2088-97.

2 Nieuwlaat R, Wilczynski N, Navarro T, et al. Interventions for enhancing medication adherence. Cochrane Database Syst Rev 2014;22.

3 Cheen MHH, Tan YZ, Oh LF, et al. Prevalence of and factors associated with primary medication non-adherence in chronic disease: a systematic review and meta-analysis. Int J Clin Pract 2019;73:e13350.

4 Naderi SH, Bestwick JP, Wald DS. Adherence to drugs that prevent cardiovascular disease: meta-analysis on 376,162 patients. Am J Med 2012;125:882-7.

5 Petry NM, Rash CJ, Byrne S, et al. Financial reinforcers for improving medication adherence: findings from a metaanalysis. Am J Med 2012;125:888-96.

6 Nanji KC, Ferris TG, Torchiana DF, et al. Overarching goals: a strategy for improving healthcare quality and safety? BMJ Qual Saf 2013;22:187-93.

7 Mongkhon P, Ashcroft DM, Scholfield CN, et al. Hospital admissions associated with medication non-adherence: a systematic review of prospective observational studies. BMJ Qual Saf 2018;27:902-14.

8 Elliott RA, Boyd MJ, Salema N-E, et al. Supporting adherence for people starting a new medication for a long-term condition through community pharmacies: a pragmatic randomised controlled trial of the new medicine service. BMJ Qual Saf 2016;25:747-58.
9 Elliott RA, Tanajewski L, Gkountouras G, et al. Cost effectiveness of support for people starting a new medication for a long-term condition through community pharmacies: an economic evaluation of the new medicine service ( $\mathrm{NmS})$ compared with normal practice. Pharmacoeconomics 2017;35:1237-55.

10 Pharmaceutical Services Negotiating Committee. New medicine service (NmS), 2019. Available: https://psnc.org.uk/ services-commissioning/advanced-services/nms/ [Accessed 22 Aug 2019].

11 Elliott RA, Boyd MJ, Tanajewski L, et al. New Medicine Service': supportingadherence in people starting a newmedication for a long-termcondition: 26-week followup of apragmatic randomisedcontrolled trial. BMJ Qual Saf 2019:1-10.

12 Nelson MR, Reid CM, Ryan P, et al. Self-Reported adherence with medication and cardiovascular disease outcomes in the second Australian National blood pressure study (ANBP2). Med J Aust 2006;185:487-9.

13 Horne R, Chapman SCE, Parham R, et al. Understanding patients' adherence-related beliefs about medicines prescribed for long-term conditions: a meta-analytic review of the Necessity-Concerns framework. PLoS One 2013;8:e80633.

14 Palacio A, Garay D, Langer B, et al. Motivational interviewing improves medication adherence: a systematic review and metaanalysis. J Gen Intern Med 2016;31:929-40.

15 Persell SD, Karmali KN, Lazar D, et al. Effect of electronic health Record-Based medication support and nurse-led medication therapy management on hypertension and medication self-management: a randomized clinical trial. JAMA Intern Med 2018;178:1069-77.

16 Elwyn G, Nelson E, Hager A, et al. Coproduction: when users define quality. BMJ Qual Saf 2019. doi:10.1136/ bmjqs-2019-009830. [Epub ahead of print: 05 Sep 2019].

17 Batalden M, Batalden P, Margolis P, et al. Coproduction of healthcare service. BMJ Qual Saf 2016;25:509-17.

18 Sabadosa KA, Batalden PB. The interdependent roles of patients, families and professionals in cystic fibrosis: a system for the coproduction of healthcare and its improvement. BMJ Qual Saf 2014;23:190-4. 